\title{
BACTÉRIAS DO ÁCIDO LÁTICO POTENCIALMENTE PROBIÓTICAS ISOLADAS DE LEITE NÃO PASTEURIZADO
}

\section{Potentially probiotic lactic acid bacteria isolated from unpasteurized milk}

\author{
Isabela Sguilla Rotta ${ }^{I}$, Marcela Fernandes da Mattal, Celso Tadeu Barbosa dos Santos ${ }^{1}$, \\ Aline Dias Paival, Alessandra Barbosa Ferreira Machado ${ }^{2 *}$
}

\section{RESUMO}

\begin{abstract}
Algumas Bactérias do Ácido Lático (BAL), quando ingeridas em quantidades adequadas, são capazes de impactar positivamente o hospedeiro, sendo consideradas probióticas. Para serem utilizadas, essas bactérias devem ter sua identidade conhecida e apresentar características específicas. Nesse estudo, BAL foram isoladas a partir de amostras de leite não pasteurizado e caracterizadas in vitro quanto ao potencial probiótico. Após isolamento, as colônias foram analisadas por coloração de Gram e teste de catalase; DNA total foi extraído e o rDNA 16S foi amplificado e sequenciado. Análise filogenética foi realizada para reconstrução da história evolutiva dos isolados. Os isolados foram avaliados quanto à resistência ao $\mathrm{pH}$ ácido e à presença de sais biliares. A atividade antagonista das bactérias isoladas foi avaliada utilizando teste de sobrecamada e o perfil de suscetibilidade a antimicrobianos foi realizado pelo método de disco difusão. Do total de 13 bactérias isoladas, três foram caracterizadas como bastonetes Gram-positivos e catalase negativos, apresentando 99\% de identidade com Lactobacillus casei, Lactobacillus paracasei e Weisella paramesenteroides. Os isolados apresentaram resistência in vitro ao estresse ácido e à presença de sais biliares; mostraram perfil de resistência semelhante aos antimicrobianos e capacidade de inibir o crescimento de bactérias potencialmente patogênicas, como Staphylococcus saprophitycus, Escherichia coli, Staphylococcus aureus, Enterococcus faecalis e
\end{abstract}

1 Universidade Federal do Triângulo Mineiro, Instituto de Ciências Biológicas e Naturais, Departamento de Microbiologia, Imunologia e Parasitologia, Uberaba, MG, Brasil.

2 Universidade Federal de Juiz de Fora, Departamento de Parasitologia, Microbiologia e Imunologia, Rua José Lourenço Kelmer, s/n, São Pedro, 36036-900, Juiz de Fora, MG, Brasil. E-mail: alessandra. machado@ufjf.edu.br

* Autor para correspondência

Recebido / Received: $28 / 05 / 2020$

Aprovado / Approved: 16/08/2020 
Enterococcus faecium. Diante das características comprovadas, as bactérias láticas isoladas neste trabalho apresentam potencial probiótico.

Palavras-chave: análise filogenética; microbiota; Lactobacillus.

\begin{abstract}
Some Lactic Acid Bacteria (LAB), when ingested in adequate quantities, are able to positively impact the host, being considered probiotics. To be used, these bacteria must have their identity known and show specific characteristics. In this study, LAB were isolated from unpasteurized milk samples and characterized in vitro for probiotic potential. After isolation, the colonies were analyzed by Gram stain and catalase test; total DNA was extracted, and the 16S rDNA was amplified and sequenced. Phylogenetic analysis was performed to reconstruct the evolutionary history of the isolates. The isolates were evaluated regarding the resistance to acidic $\mathrm{pH}$ and the presence of bile salts. The antagonistic activity of the isolated bacteria was evaluated by the overlay test and the antimicrobial susceptibility profile was performed by the disc diffusion method. Of the 13 isolated bacteria, three were characterized as Gram positive and catalase negative rods, showing $99 \%$ of identity with Lactobacillus casei, Lactobacillus paracasei, and Weisella paramesenteroides. The isolates showed in vitro resistance to acidic stress and to the presence of bile salts; showed similar antimicrobial resistance profile and ability to inhibit the growth of potentially pathogenic bacteria, such as Staphylococcus saprophitycus, Escherichia coli, Staphylococcus aureus, Enterococcus faecalis, and Enterococcus faecium. In view of the proven characteristics, the lactic acid bacteria isolated in this work have probiotic potential.
\end{abstract}

Keywords: phylogenetic analysis; microbiota; Lactobacillus.

\section{INTRODUÇÃO}

O trato intestinal (TI) alberga uma população diversa e complexa de microrganismos denominada microbiota intestinal. Sua colonização tem início no nascimento e perdura ao longo da vida, sofrendo alterações resultantes de características genéticas e imunológicas do hospedeiro, além de fatores exógenos, como tratamento com antimicrobianos, contaminação ambiental, dieta e exercícios físicos (CRUZ et al., 2015; PINTO, 2017).

A microbiota intestinal estabelece uma relação importante com o organismo humano, modulando o sistema imunológico e o metabolismo, auxiliando na digestão e absorção de nutrientes e atuando como barreira contra agentes agressores, ao competir por nutrientes e sítios de ligação, produzir substâncias antimicrobianas e evitar a penetração de potenciais patógenos na mucosa intestinal (PASSOS; MORAESFILHO, 2017).

$\mathrm{O}$ equilíbrio da microbiota pode ser assegurado por suplementação sistemática da dieta com alimentos funcionais, os quais, além de fornecerem nutrição básica, promovem a saúde e o bem-estar (CRUZ et al., 2015; OLIVEIRA et al., 2017). Dentre os alimentos funcionais destacam-se os probióticos, definidos como microrganismos vivos que, quando administrados em quantidades adequadas, exercem efeitos benéficos ao 
hospedeiro. Para serem considerados probióticos os microrganismos devem ser isolados, purificados e seus efeitos benéficos cientificamente comprovados (FAO; WHO, 2001).

Os microrganismos considerados probióticos devem apresentar resistência ao $\mathrm{pH}$ ácido do estômago, aos sais biliares e às enzimas pancreáticas e digestivas, capacidade de aderência e colonização das células intestinais, atividade antagonista contra bactérias potencialmente patogênicas, resistência intrínseca aos principais antimicrobianos utilizados clinicamente e capacidade imunomoduladora (VENTURA et al., 2012; LECLERCQ et al., 2017). Testes in vitro e in vivo devem ser capazes de certificar tais propriedades (SUÁREZ, 2015).

Dentre as bactérias reconhecidamente probióticas, muitas fazem parte do grupo heterogêneo denominado Bactérias do Ácido Lático (BAL), que compreendem um grupo de bactérias Gram-positivas, cocos, cocobacilos ou bacilos, catalase negativas, não formadoras de endósporos e que possuem o ácido lático como principal produto da fermentação de carboidratos (SUÁREZ, 2015). Muitas dessas bactérias são empregadas na indústria alimentícia, sendo que diversas espécies apresentam características tecnológicas propostas a microrganismos probióticos (CARVALHO et al., 2017). O grupo das BAL compreende os seguintes gêneros: Carnobacterium, Enterococcus, Lactococcus, Lactobacillus, Lactosphaera, Leuconostoc, Oenococcus, Pediococcus, Streptococcus, Vagococcus, Weissella, Tetragenococcus e Bifidobacterium (FERREIRA, 2012).

Os produtos lácteos são constituintes dos hábitos alimentares da maior parte da população, sendo recomendados como alimentos benéficos por órgãos promotores de saúde, como a Organização Mundial de Saúde (OMS) e o Ministério da Saúde. Nas últimas décadas, observou-se um evidente crescimento da preocupação com a saúde associada à nutrição. Nesse cenário, nota-se a expansão do uso de probióticos, bem como dos estudos acerca dos benefícios relacionados a esse consumo (FAO; WHO, 2001).

O objetivo deste estudo foi realizar o isolamento e a caracterização molecular e fisiológica de BAL prospectadas a partir de amostras de leite não pasteurizado provenientes de rebanho bovino da cidade de Uberaba, Minas Gerais.

\section{MATERIAL E MÉTODOS}

As amostras de leite bovino foram coletadas em uma fazenda na cidade de Uberaba, Minas Gerais, e transportadas em caixas de isopor com gelo até o laboratório de Microbiologia da Universidade Federal do Triângulo Mineiro (UFTM), onde permaneceram refrigeradas até o momento das análises.

\section{Isolamento e seleção das bactérias de interesse}

As amostras de leite foram diluídas (até $\left.10^{-3}\right)$ em água peptonada estéril $(0,2 \%)$ e inoculadas em placas de Petri contendo ágar MRS (Man, Rogosa e Sharpe, Kasvi, Itália). As placas foram incubadas em microaerofilia, a $37^{\circ} \mathrm{C}$, por 48 horas. Após crescimento, as colônias foram novamente estriadas em ágar MRS e analisadas quanto às características morfotintoriais, por meio da coloração de Gram. Bastonetes Gram-positivos foram selecionados nesta etapa, sendo então realizado o teste de catalase, utilizando peróxido de hidrogênio (30\%). Somente os isolados Gram-positivos, bastonetes, catalase negativos foram selecionados. As culturas estoque foram mantidas em meio BHI (Brain Heart Infusion, Kasvi, Itália) contendo glicerol $(20 \%)$ e armazenadas em freezer a $-20^{\circ} \mathrm{C}$. 


\section{Extração de DNA total das bactérias isoladas}

Para extração do DNA total foi utilizada metodologia descrita por Oliveira et al. (2002), com modificações. As bactérias foram cultivadas em placas contendo ágar MRS, à $37{ }^{\circ} \mathrm{C}$, em microaerofilia, por 24 horas. A cultura foi ressuspendida em $500 \mu \mathrm{L}$ de $\mathrm{TE}$ (10 mM de Tris-HCl; pH 8.0, 1 mM EDTA) e centrifugada (12000 rpm, 2 minutos). O sobrenadante foi descartado e o pellet ressuspendido em $200 \mu \mathrm{L}$ de solução de lisozima $(4 \mathrm{mg} / \mathrm{mL})$. A mistura foi incubada por 1 hora, a $50{ }^{\circ} \mathrm{C}$. Posteriormente foi adicionado proteinase $\mathrm{K}(100 \mu \mathrm{L}, 10 \mathrm{mg} / \mathrm{mL})$ e a mistura foi novamente incubada a $50{ }^{\circ} \mathrm{C}$, por 1 hora. Após incubação, as enzimas foram inativadas com água em ebulição, por 10 minutos. Foi adicionado fenol-clorofórmioálcool isoamílico $(400 \mu \mathrm{L}, 25: 24: 1)$ e a mistura foi novamente centrifugada (12000 rpm, 5 minutos). Após retirada da fase aquosa foi adicionado igual volume de clorofórmio-álcool isoamílico (24:1) e a mistura foi centrifugada (12000 rpm, 5 minutos). Novamente retirou-se a fase aquosa (aproximadamente $200 \mu \mathrm{L}$ ) e foi adicionado $10 \%$ de acetato de sódio ( $3 \mathrm{M}, \mathrm{pH} 6,0)$ e 2,5 vezes o volume de etanol absoluto gelado. Os tubos foram incubados a $20{ }^{\circ} \mathrm{C}$, por 30 minutos, e centrifugados $(12000 \mathrm{rpm}, 10$ minutos.). O sobrenadante foi descartado e o pellet foi lavado com etanol $70 \%$ gelado (1 mL) e centrifugado (13000 rpm, 20 minutos). Ao final, desprezou-se a parte líquida e o tubo foi seco à temperatura ambiente. A quantificação do DNA foi realizada em espectrofotômetro NanoDrop (Thermo Scientific $\left.^{\circledR}\right)$ e as amostras foram diluídas para $50 \mathrm{ng} / \mu \mathrm{L}$ para a realização de PCR.

\section{Amplificação do rDNA16S e sequenciamento}

O rDNA 16S foi amplificado utilizando os primers universais 27F (AGA GTT TGA TCC TGG CTC AG) e 1492R (GGT TAC CTT GTT ACG ACT) (SUZUKI et al., 1998). As reações de amplificação foram realizadas em um volume total de $25 \mu \mathrm{L}$. A PCR foi realizada utilizando as seguintes condições: temperatura inicial de desnaturação a $95{ }^{\circ} \mathrm{C}$, por 5 minutos, seguida de 35 ciclos de $95^{\circ} \mathrm{C}$, por 30 segundos, para a desnaturação, $60^{\circ} \mathrm{C}$, por 30 segundos, para anelamento dos primers, e $72{ }^{\circ} \mathrm{C}$, por 60 segundos, para a extensão dos primers. O ciclo de amplificação foi seguido por uma extensão final a $72{ }^{\circ} \mathrm{C}$, por 7 minutos, e os tubos foram mantidos a $4{ }^{\circ} \mathrm{C}$. Os produtos de amplificação foram submetidos à eletroforese em gel de agarose $(1,5 \%)$. O gel foi corado com brometo de etídio $(0,2 \mu \mathrm{g} / \mathrm{mL})$ e fotodocumentado sob luz ultravioleta. Os produtos de PCR foram purificados utilizando o Protocolo 1 de purificação (Purification and concentration of DNA fragments from enzymatic reactions) do Kit Invisorb fragments Clean up (Stratec Molecular). Os produtos foram sequenciados pela empresa Myleus Biotecnologia e a análise das sequências foram realizadas utilizando o programa Basic Local Alignment Search Tool para nucleotídeos (BLASTn).

\section{Análise filogenética}

Para cada sequência obtida foi feita uma busca de identidade com a utilização do programa BLASTn. As sequências foram utilizadas para a reconstrução de árvores filogenéticas por Máxima Parcimônia no programa MEGA X. A Máxima Parcimônia é um método de reconstrução filogenética que presume que a melhor hipótese filogenética é aquela que envolve menor número de passos evolutivos, isto é, o menor número de mudanças que expliquem a variação de uma matriz de dados (POSADA; BUCKLEY, 2004). Após selecionar as sequências, realizou-se um alinhamento global com o 
programa Clustal X. Em seguida o alinhamento foi convertido para o formato MEGA. Uma árvore filogenética foi reconstruída com o auxílio do programa MEGA X, utilizando o método de Máxima Parcimônia com bootstrap igual a 1000 .

\section{Resistência ao pH ácido}

Para avaliar a resistência ao $\mathrm{pH}$ ácido foi utilizada metodologia descrita por Erkkilä e Petäjä (2000), com modificações. Culturas pré-ativadas das bactérias selecionadas foram transferidas (inóculo de $1 \mathrm{~mL}$ ) para caldo MRS $(10 \mathrm{~mL})$ e incubadas a $37^{\circ} \mathrm{C}$, por 12 horas, em microaerofilia. Após incubação, o meio de cultura foi centrifugado $(4000 \mathrm{rpm}$, 15 minutos, $4{ }^{\circ} \mathrm{C}$ ), o pellet foi lavado por duas vezes com água peptonada e ressuspendido em $10 \mathrm{~mL}$ de água peptonada, para obtenção de uma suspensão contendo aproximadamente $10^{9} \mathrm{UFC} / \mathrm{mL}$. Uma alíquota de $1 \mathrm{~mL}$ dessa suspensão foi transferida para tubos contendo $9 \mathrm{~mL}$ de caldo MRS, com pH 3,5. O pH ácido foi obtido através da adição de ácido clorídrico $1 \mathrm{M}$ com mensuração do $\mathrm{pH}$ através de medidor de $\mathrm{pH}$ digital. Como controle foi utilizado meio MRS $\mathrm{pH}$ 6,7. Os tubos foram incubados a $37{ }^{\circ} \mathrm{C}$, em microaerofilia, sendo coletadas amostras nos tempos 0,2 e 4 horas de incubação para verificação da viabilidade celular, pela determinação de $\mathrm{UFC} / \mathrm{mL}$, utilizando a técnica de semeadura em profundidade (pour plate) e meio MRS. $\mathrm{O}$ experimento foi realizado em duplicata.

\section{Resistência à presença de sais biliares}

Para avaliar a tolerância a sais biliares foi utilizada metodologia descrita por Pennacchia et al. (2004), com modificações. Culturas pré-ativadas das bactérias láticas selecionadas foram transferidas (inóculo de $1 \mathrm{~mL}$ ) para caldo MRS $(10 \mathrm{~mL})$ e incubadas a $37^{\circ} \mathrm{C}$, por 12 horas em microaerofilia. Após incubação, o meio de cultura foi centrifugado (4000 rpm, 15 minutos, $4{ }^{\circ} \mathrm{C}$ ), o pellet foi lavado por duas vezes com água peptonada e ressuspendido em $10 \mathrm{~mL}$ de água peptonada, para obtenção de uma suspensão contendo aproximadamente $10^{9} \mathrm{UFC} / \mathrm{mL}$. Uma alíquota de $1 \mathrm{~mL}$ dessa suspensão foi transferida para tubos contendo $9 \mathrm{~mL}$ de caldo MRS adicionado de $0,3 \%$ de sais biliares. Como controle foi utilizado meio MRS sem adição de sais biliares. Os tubos foram incubados a $37^{\circ} \mathrm{C}$, em microaerofilia, sendo coletadas amostras nos tempos 0,2 e 4 horas de incubação para verificação da viabilidade celular, pela determinação de UFC/mL, utilizando a técnica de semeadura em profundidade (pour plate) e meio MRS. $\mathrm{O}$ experimento foi realizado em duplicata.

\section{Inibição do crescimento de bactérias in vitro}

A atividade antagonista das bactérias láticas selecionadas foi avaliada pelo método de sobrecamada (BOOTH et al., 1977), utilizando como microrganismos indicadores bactérias Gram-positivas e Gram-negativas de referência e potenciais patógenos. Os isolados foram cultivados em meio MRS sólido, a $37{ }^{\circ} \mathrm{C}$ em microaerofilia, e as diferentes colônias obtidas foram transferidas para outra placa contendo meio MRS. Após incubação e desenvolvimento das colônias foram vertidos $5 \mathrm{~mL}$ de meio BHI semi-sólido (0,75\% de ágar), previamente inoculado com o microrganismo indicador. As placas foram incubadas por até 48 horas, em microaerofilia, a $37{ }^{\circ} \mathrm{C}$. A atividade antimicrobiana foi determinada pela presença de halos de inibição ( $>6 \mathrm{~mm}$ de diâmetro) do crescimento do microrganismo indicador em torno das colônias dos isolados avaliados.

Perfil de suscetibilidade aos antimicrobianos

O antibiograma foi realizado para 
cada isolado de acordo com Charteris et al. (1998), utilizando o método de disco difusão, como recomendado pelo Clinical \& Laboratory Standards Institute (CLSI, 2017). Os isolados foram cultivados em ágar MRS, em microaerofilia, a $37^{\circ} \mathrm{C}$, durante 24 horas. Em seguida, colônias foram transferidas para tubos com $3,5 \mathrm{~mL}$ de solução salina $(0,85 \%)$, para obtenção de concentração correspondente a 0,5 na escala McFarland $\left(10^{8} \mathrm{UFC} / \mathrm{mL}\right)$. As amostras foram inoculadas sobre a superfície de placas de Petri $(15 \mathrm{~cm}$ de diâmetro), contendo ágar Muller Hinton, utilizando $s w a b$. Os discos contendo as drogas antimicrobianas foram dispostos sobre a placa, em pontos equidistantes, sob leve pressão, com o auxílio de uma pinça estéril. Foram avaliadas as seguintes drogas: ampicilina $(10 \mu \mathrm{g})$, amicacina (30 $\mu \mathrm{g})$, clindamicina $(2 \mu \mathrm{g})$, cloranfenicol (30 $\mu \mathrm{g})$, eritromicina $(15 \mu \mathrm{g})$, gentamicina (10 $\mu \mathrm{g})$, oxacilina $(1 \mu \mathrm{g})$, penicilina $\mathrm{G}$ (1U), rifampicina $(5 \mu \mathrm{g})$, tetraciclina $(30 \mu \mathrm{g}) \mathrm{e}$ vancomicina $(30 \mu \mathrm{g})$. Após 10 minutos em temperatura ambiente, as placas foram incubadas em microaerofilia, a $37{ }^{\circ} \mathrm{C}$, por 18 horas. Após incubação foi realizada a medida dos diâmetros dos halos de inibição ao redor do disco de antimicrobiano (em milímetros), utilizando régua. Os resultados foram expressos quantitativamente, para a classificação qualitativa dos microrganismos em sensível, resistência intermediária ou resistente às drogas antimicrobianas testadas. Os pontos de corte utilizados foram aqueles descritos por Charteris et al. (1998) e pelo CLSI (2017).

\section{RESULTADOS E DISCUSSÃO}

Após inoculação das amostras de leite não pasteurizado em meio MRS foi possível o isolamento de 13 bactérias distintas. Todos os isolados foram caracterizados como Grampositivos e catalase negativos. Em relação à morfologia, nove linhagens apresentaram forma de cocos, três de bacilos e uma apresentou forma coco-bacilar. Com isso, dentre os isolados obtidos, aqueles nomeados como 2.6, 2.9 e 2.11 foram selecionados para os experimentos subsequentes por apresentarem as características iniciais de interesse.

O leite não pasteurizado apresenta grande diversidade de bactérias, o que pode ser afetado por inúmeros fatores como, por exemplo, o nível nutricional do animal, as técnicas de ordenha utilizadas e as condições sanitárias em que os animais são mantidos. É necessário considerar ainda a idade do animal, uma vez que pode afetar consideravelmente a quantidade de bactérias potencialmente benéficas presentes em seu leite (WENDLING; WESCHENFELDER, 2013). Essas variáveis podem explicar o isolamento de poucos microrganismos pertencentes ao grupo de BAL em estudos de prospecção.

A caracterização molecular de procariotos oferece oportunidade para o melhor entendimento de características fenotípicas, fisiológicas e ecológicas desses microrganismos (KANT et al., 2017), contribuindo para um estudo mais satisfatório de bactérias potencialmente probióticas. Os isolados 2.6, 2.9 e 2.11 apresentaram $99 \%$ de identidade com Weisella paramesenteroides, Lactobacillus paracasei e Lactobacillus casei, respectivamente (Tabela 1). As sequências parciais do rDNA $16 \mathrm{~S}$ obtidas foram depositadas no banco de dados GenBank, com os números de acesso SUB7310347 Seq3 MT431562 (Weisella paramesenteroides 2.6), SUB7310347 Seq2 MT431561 (Lactobacillus paracasei 2.9) e SUB7310347 Seq1 MT431560 (Lactobacillus casei 2.11).

A partir da identificação genética foi realizada análise filogenética para reconstrução da história evolutiva das linhagens isoladas neste trabalho (Figura 1). Dentre 
as inúmeras técnicas de biologia molecular, a análise comparativa de genes tem sido amplamente empregada, principalmente a análise da região gênica que codifica o rDNA 16S (SANSCHAGRIN; YERGEAU, 2014). Essa técnica é utilizada com finalidade taxonômica e filogenética, de modo que essa região é uma sequência que apresenta características conservadas ao longo da evolução e pode auxiliar no entendimento de como os microrganismos se inter-relacionam (SILVA, 2016; KANT et al., 2017).
Bactérias probióticas devem resistir às condições adversas do trato gastrointestinal de modo a atingirem o intestino em sua forma viável. Portanto, a resistência in vitro ao $\mathrm{pH}$ ácido e aos sais biliares são características essenciais para que uma linhagem possa ser considerada potencialmente probiótica, pois revelam uma maior chance de a referida linhagem sobreviver à passagem pelo estômago e duodeno in vivo (WENDLING; WESCHENFELDER, 2013).

No teste de resistência à acidez,

Tabela 1 - Identificação genética das linhagens bacterianas isoladas a partir de leite bovino não pasteurizado

\begin{tabular}{ccc}
\hline Linhagens & Identidade (Blastn)* $^{*}$ & Microrganismo* $^{*}$ \\
\hline 2.6 & $99 \%$ & Weisella paramesenteroides CE. 3.4 \\
2.9 & $99 \%$ & Lactobacillus paracasei \\
2.11 & $99 \%$ & Lactobacillus casei NIF1AN12 \\
\hline
\end{tabular}

* Dados obtidos no banco de dados NCBI (Nacional Center for Biotechonology Information)

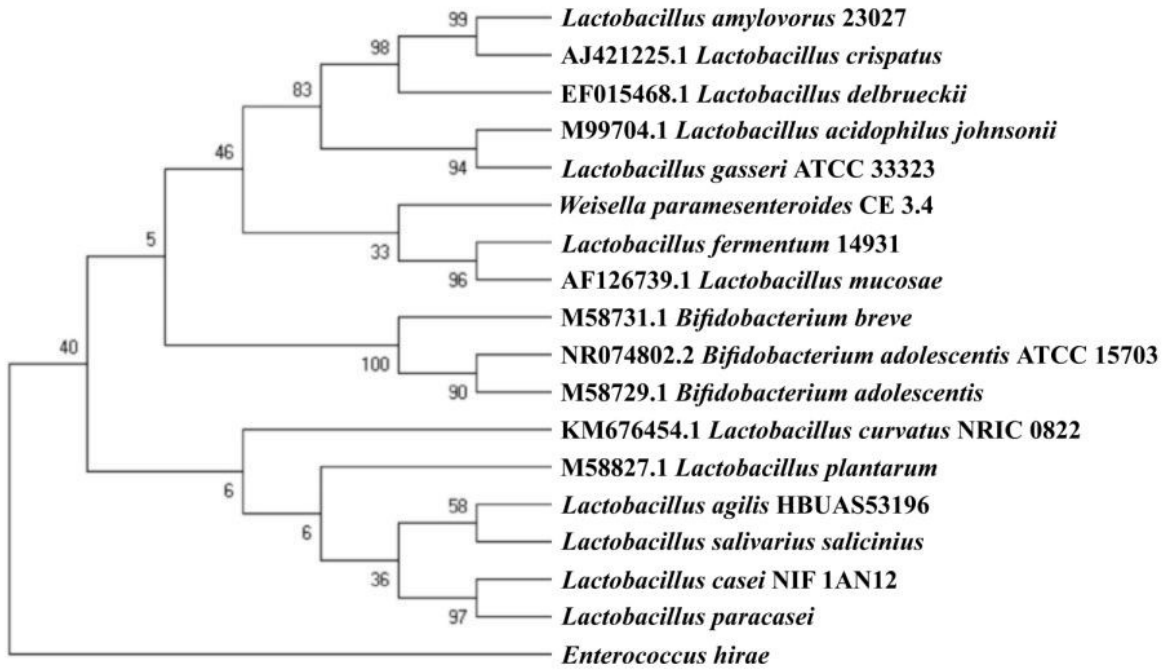

Figura 1 - Reconstrução da história evolutiva das linhagens de BAL isoladas a partir de leite bovino não pasteurizado 
Weisella paramesenteroides 2.6 manteve a viabilidade inicial $\left(10^{7} \mathrm{UFC} / \mathrm{mL}\right)$ ao longo das $4 \mathrm{~h}$ de exposição ao $\mathrm{pH}$ ácido, enquanto Lactobacillus paracasei 2.9 e Lactobacillus casei 2.11 apresentaram diminuição de até um ciclo logarítmico, após $4 \mathrm{~h}$ e $2 \mathrm{~h}$ em meio MRS com $\mathrm{pH} 3,5$, respectivamente (Tabela 2). Guimarães et al. (2018) ao avaliarem BAL provenientes do leite de transição bovino fermentado, observaram característica de resistência ao $\mathrm{pH}$ ácido semelhante às apresentadas neste estudo. Fusco et al. (2015) também indicaram que Weissella paramesenteroides é tolerante a $\mathrm{pH}$ abaixo de 5 , corroborando com os resultados obtidos neste trabalho.

Após quatro horas de exposição aos sais biliares $(0,3 \%), W$. paramesenteroides 2.6 e L. paracasei 2.9 mantiveram a viabilidade inicial $\left(10^{8} \mathrm{UFC} / \mathrm{mL}\right)$, enquanto L. casei 2.11 apresentou redução de um ciclo logarítmico (Tabela 3). Mangoni et al. (2011) avaliaram o crescimento de Lactobacillus spp. provenientes de suínos em meio acrescido de $0,3 \%$ de sais biliares, sendo duas linhagens tolerantes aos sais biliares. Alvim (2011) também demonstrou que a maioria das BAL isoladas de suínos foram tolerantes à presença de sais biliares.

A inibição de bactérias potencialmente patogênicas é uma das principais propriedades desejáveis para linhagens probióticas (LECLERCQ et al., 2017). No teste de sobrecamada, as culturas são separadas dos microrganismos indicadores por uma camada de ágar semi-sólido, que impede o contato direto entre elas. Dessa maneira, é possível avaliar a produção de substâncias

Tabela 2 - Efeito do estresse ácido (pH 3,5) sobre a sobrevivência (UFC/mL) das linhagens bacterianas isoladas a partir de leite bovino não pasteurizado; como controle foi utilizado meio MRS pH 6,7

\begin{tabular}{ccccccc}
\hline \multirow{2}{*}{ Isolados } & \multicolumn{3}{c}{$\mathrm{UFC} / \mathrm{mL} \mathrm{pH} 6,7$} & \multicolumn{3}{c}{$\mathrm{UFC} / \mathrm{mL} \mathrm{pH} \mathrm{3,5}$} \\
\cline { 2 - 7 } & $0 \mathrm{~h}$ & $2 \mathrm{~h}$ & $4 \mathrm{~h}$ & $0 \mathrm{~h}$ & $2 \mathrm{~h}$ & $4 \mathrm{~h}$ \\
\hline 2.6 & $7,5 \times 10^{7}$ & $2,02 \times 10^{8}$ & $3,77 \times 10^{8}$ & $3,7 \times 10^{7}$ & $3,2 \times 10^{7}$ & $3,7 \times 10^{7}$ \\
2.9 & $1,03 \times 10^{8}$ & $1,03 \times 10^{8}$ & $3,54 \times 10^{8}$ & $1,77 \times 10^{8}$ & $1,29 \times 10^{8}$ & $6,7 \times 10^{7}$ \\
2.11 & $2,05 \times 10^{8}$ & $1,98 \times 10^{8}$ & $1,56 \times 10^{8}$ & $1,64 \times 10^{8}$ & $9,9 \times 10^{7}$ & $2,7 \times 10^{7}$ \\
\hline
\end{tabular}

Tabela 3 - Efeito de sais biliares sobre a sobrevivência (UFC/mL) das linhagens e meio controle (sem adição de sais biliares) e em meio com adição de $0,3 \%$ de sais

\begin{tabular}{ccccccc}
\hline \multirow{2}{*}{ Isolados } & \multicolumn{3}{c}{ UFC/mL 0\% Sais } & \multicolumn{3}{c}{ UFC/mL 0,3\% Sais } \\
\cline { 2 - 6 } & $0 \mathrm{~h}$ & $2 \mathrm{~h}$ & $4 \mathrm{~h}$ & $0 \mathrm{~h}$ & $2 \mathrm{~h}$ & $4 \mathrm{~h}$ \\
\hline 2.6 & $1,95 \times 10^{8}$ & $3,1 \times 10^{8}$ & $8 \times 10^{8}$ & $1,23 \times 10^{8}$ & $1,24 \times 107$ & $2,44 \times 10^{8}$ \\
2.9 & $2,7 \times 10^{8}$ & $2,8 \times 10^{8}$ & $1,96 \times 10^{9}$ & $1,56 \times 10^{8}$ & $2,33 \times 10^{8}$ & $2,22 \times 10^{8}$ \\
2.11 & $8,1 \times 10^{6}$ & $1,88 \times 10^{7}$ & $2,96 \times 10^{7}$ & $1,27 \times 10^{7}$ & $8,7 \times 10^{6}$ & $9,7 \times 10^{6}$ \\
\hline
\end{tabular}


extracelulares e difusíveis como, por exemplo, ácidos orgânicos (como ácido lático), peróxido de hidrogênio, radicais livres, diacetil e peptídeos (como as bacteriocinas), uma vez que o composto gerado deve difundirse no ágar para exercer seu efeito sobre as bactérias indicadoras (BOOTH et al., 1977; LECLERCQ et al., 2017).

Atividade antagonista foi demonstrada pelas três linhagens avaliadas neste estudo, com destaque para $L$. casei 2.11 , que inibiu cinco das seis bactérias indicadoras testadas, incluindo Escherichia coli ATCC 35218, uma bactéria Gram-negativa (Tabela 4).
Staphylococcus aureus ATCC 25923 foi a única bactéria indicadora inibida pelas três BAL isoladas neste trabalho, enquanto o crescimento de Enterococcus gallinarum ATCC 12359 não foi inibido por nenhuma das bactérias.

Um bom probiótico não deve carregar genes de resistência a antimicrobianos (MONTORO et al., 2018), isto é, apesar de muitas linhagens de BAL, especialmente as de Lactobacillus spp., apresentarem resistência a determinados antimicrobianos, essa resistência normalmente é não transferível. Todas as linhagens avaliadas mostraram-

Tabela 4 - Inibição de crescimento in vitro de bactérias potencialmente patogênicas ou deterioradoras de alimentos por bactérias láticas isoladas a partir de leite bovino não pasteurizado

\begin{tabular}{cccc}
\hline Indicadoras & \multicolumn{3}{c}{ Isolados } \\
\cline { 2 - 4 } & 2.6 & 2.9 & 2.11 \\
\hline Enterococcus faecium 7171 & - & - & + \\
Enterococcus faecalis 29212 & + & - & + \\
Enterococcus gallinarum 12359 & - & - & + \\
Staphylococcus saprophyticus 35552 & + & - & + \\
Staphylococcus aureus 25923 & + & + & + \\
Escherichia coli 35218 & + & - & +
\end{tabular}

Legenda: (+) inibição; (-) não inibição.

Tabela 5 - Perfil de suscetibilidade a antimicrobianos de bactérias láticas isoladas a partir de leite bovino não pasteurizado

\begin{tabular}{cccccccccccc}
\hline \multirow{2}{*}{ Isolados } & \multicolumn{10}{c}{ Antimicrobianos } \\
\cline { 2 - 10 } & AMK & AMP & CLI & CHL & ERI & GEN & OXA & PEN & RIF & TCY & VAN \\
\hline 2.6 & R & S & S & S & S & R & R & S & RI & S & R \\
2.9 & R & S & S & S & S & R & S & S & S & S & R \\
2.11 & R & S & S & S & S & R & RI & S & S & S & R \\
\hline
\end{tabular}

Legenda: $\mathrm{AMK}=$ amicacina; $\mathrm{AMP}=$ ampicilina $\mathrm{CLI}=$ clindamicina $; \mathrm{CHL}=$ cloranfenicol; $\mathrm{ERI}=$ eritromicina; $\mathrm{GEN}=$ gentamicina; $\mathrm{OXA}=$ oxacilina; $\mathrm{PEN}=$ penincilina $\mathrm{G} ; \mathrm{RIF}=$ rifampicina; $\mathrm{TCY}=$ tetraciclina; $\mathrm{VAN}=$ vancomicina. $\mathrm{S}=$ sensível; $\mathrm{R}$ = resistente; $\mathrm{RI}=$ resistência intermediaria. 
se resistentes à amicacina, gentamicina e vancomicina, sendo sensíveis à ampicilina, clindamicina, cloranfenicol, eritromicina, penicilina e tetraciclina (Tabela 5).

As linhagens estudadas apresentaram resistência à vancomicina, reforçando estudos que já mostraram linhagens de Lactobacillus e Weissella resistentes a esse glicopeptídeo (COPPOLA; TURNES, 2004; OUOBA et al., 2008; RODRÍGUEZ-ALONSO et al., 2009). Tais microrganismos possuem o sítio de reconhecimento do glicopeptídeo alterado, dificultando a ligação do antibiótico ao seu alvo. Esse mecanismo tem sido relacionado à microrganismos resistentes intrinsicamente à vancomicina (OUOBA et al., 2008), não passível de transferência.

\section{CONCLUSÃO}

Os resultados encontrados sugerem que Weisella paramesenteroides 2.6, Lactobacillus paracasei 2.9 e Lactobacillus casei 2.11, isolados de leite bovino não pasteurizado na cidade de Uberaba - MG, apresentam características promissoras para serem considerados como potencialmente probióticos. Estudos adicionais devem ser realizados para esclarecer os mecanismos moleculares de probiose e os efeitos dessas linhagens in vivo para que possam ser utilizadas para o desenvolvimento de probióticos eficazes.

\section{REFERÊNCIAS BIBLIOGRÁFICAS}

ALVIM, L. B. Identificação molecular e seleção de bactérias láticas com potencial probiótico isoladas de diferentes mucosas de suínos. 2011. 66 f. Dissertação (Mestrado em Genética) - Universidade Federal de Minas Gerais, Belo Horizonte, 2011.

BOOTH, P. B. et al. Selective depression of blood group antigens associated with hereditary ovalocytosis among Melanesians.
Vox sanguinis, v. 32, n. 2, p. 99-110, 1977. DOI: 10.1111/j.1423-0410.1977.tb00612.x

CARVALHO, P. T. et al. Análises de bactérias ácidos láticas, de $\mathrm{pH}$ e acidez em amostras de leites fermentados comercializados no município de Sete Lagoas-MG. Brazilian Journal of Food Research, v. 8, n. 3, p.1221, 2017. DOI: 10.3895/rebrapa.v8n3.3989

CHARTERIS, A. et al. Antibiotic susceptibility of potentially probiotic Lactobacillus Specie. Journal of Food Protection, v. 61, n. 12, p. 1636-1643, 1998. DOI: $10.4315 / 0362-028 x-61.12 .1636$

CLSI - Clinical and Laboratory Standards Institute. M100-S26: Performance standards for antimicrobial susceptibility testing. 26. ed. Wayne: CLSI, 2017. 256 p.

COPPOLA, R.; TURNES, C. Probióticos e resposta imune. Ciência Rural, v. 34, n. 4, p.1297-1303, 2004. DOI: 10.1590/s010384782004000400056

CRUZ, G. B. V. et al. Prospecção tecnológica de micro-organismos probióticos com atividade imunomoduladora. Cadernos de Prospecção, v. 8, n. 4, p. 684-690, 2015. DOI: 10.9771/s.cprosp.2015.008.076

ERKKILÄ, S.; PETÄJÄ, E. Screening of commercial meat starter culture at low $\mathrm{pH}$ and in presence of bile salts for potential probiotic use. Meat Science, v. 55, n. 3, p. 297-300, 2000. DOI: 10.1016/S0309-1740(99)00156-4

FAO - Food and Agriculture Organization of the United Nations; WHO - World Health Organization. Health and nutritional properties of probiotics in food including powder milk with live lactic acid bacteria. Report of a Joint FAO/WHO Expert Consultation on evaluation of health and 
nutritional properties of probiotics in food including powder milk with live lactic acid bacteria. Córdoba: FAO; WHO, 2001. 34 p. Disponível em: http://www.fao.org/tempref/ docrep/fao/meeting/009/y6398e.pdf

FERREIRA, C. L. L. F. Grupo de bactérias lácticas e aplicação tecnológica de bactérias probióticas. In: FERREIRA, C. L. L. F. (ed.). Prebióticos e Probióticos: atualização e prospecção. 1. ed. Rio de Janeiro: Editora Rubio, 2012. cap. 1. p. 1-28.

FUSCO, V. et al. The genus Weissella: taxonomy, ecology and biotechnological potential. Frontiers in Microbiology, v. 6, p. 1-22, 2015. DOI: $10.3389 /$ fmicb. 2015.00155

GUIMARÃES, F. et al. Seleção de bactérias láticas com potencial probiótico provenientes do leite de transição bovino fermentado. Interciência, v. 43, n. 2, p. 132-136, 2018.

KANT, R.; PALVA, A.; OSSOWSKI, I. An in silico pan-genomic probe for the molecular traits behind Lactobacillus ruminis gut autochthony. Plos One, v. 12, n. 4, p. 1-26, 2017. DOI: 10.1371/journal.pone.0175541

LECLERCQ, S. et al. Low-dose penicillin in early life induces long-term changes in murine gut microbiota, brain cytokines and behavior. Nature Communications, v. 8, n. 15062, p. 1-12, 2017. DOI: $10.1038 /$ ncomms 15062

MANGONI, J. et al. Potencial probiotic lactobacilli of pig origin. Acta ScientiarumAnimal Sciences, v. 33, n. 3, p. 267-272, 2011. DOI: 10.4025 /actascianimsci.v33i3.9826

MONTORO, D. T. et al. A revised airway epithelial hierarchy includes CFTR-expressing ionocytes. Nature, v. 560, n. 7718, p. 319-324, 2018. DOI: $10.1038 / \mathrm{s} 41586-018-0393-7$

OLIVEIRA, G. L. V. et al. Intestinal dysbiosis and probiotic applications in autoimune diseases. Immunology, v. 152, n. 1, p. 1-12, 2017. DOI: $10.1111 / \mathrm{imm} .12765$

OLIVEIRA, S. D. et. al. Detection and identification of Salmonella from poultryrelated samples by PCR. Veterinary Microbiology, v. 87, n. 1, p. 25-35, 2002. DOI: $10.1016 / \mathrm{s} 0378-1135(02) 00028-7$

OUOBA, L. I. I.; LEI, V.; JENSEN, L. B. Resistance of potential probiotic lactic acid bacteria and bifidobacteria of African and European origin to antimicrobials: Determination and transferability of the resistance genes to other bacteria. International Journal of Food Microbiology, v. 121 , n. 2 , p. $217-224$, 2008. DOI: $10.1016 /$ j. ijfoodmicro.2007.11.018

PASSOS, M. C. F.; MORAES-FILHO, J. P. Intestinal microbiota in digestive diseases. Arquivos de Gastroenterologia, v. 54, n. 3, p. 255-262, 2017. DOI: $10.1590 / \mathrm{s} 0004-$ 2803.201700000-31

PENNACCHIA, C. et. al. Selection of Lactobacillus strains from fermented sausages for their potential use as probiotics. Meat Science, v. 67, n. 2, p. 309-317, 2004. DOI: 10.1016/j.meatsci.2003.11.003

PINTO, R. M. S. P. Efeito metabólico e dos probióticos, na microbiota intestinal, na prevenção do cancro do colo-rectal. 2017. 18 f. Trabalho de Conclusão de Curso (Graduação em Nutrição) - Faculdade de Ciência da Nutrição e Alimentação da Universidade do Porto, Porto, 2017.

POSADA, D.; BUCKEY T. R. Model selection and model averaging in phylogenetics: advantages of AKAIKE information criterion and Bayesian approaches over likelihood ratio tests. Systematic Biology, 
v. 53, n. 5, p. 793-808, 2004. DOI: $10.1080 / 10635150490522304$

RODRIGUEZ-ALONSO, P. et al. Antibiotic resistance in Lactic Acid Bacteria and Micrococcaceae/Staphylococcaceae isolates from artesanal raw milk cheeses, and potential implications on cheese making. Journal of Food Science, v. 74, n. 6, p. 284-293, 2009. DOI: $10.1111 /$ j.1750-3841.2009.01217.x

SANSCHAGRIN, S.; YERGEAU, E. Nextgeneration sequencing of $16 \mathrm{~S}$ ribosomal RNA gene amplicons. Journal of Visualized Experiments, v. 90, n. 51709, p. 1-6, 2014. DOI: $10.3791 / 51709$

SILVA, J. G. Identificação molecular de bactérias ácido láticas e propriedades probióticas in vitro de Lactobacillus spp. isolados de queijo Minas artesanal de Araxá, Minas Gerais. 2016. 82 f. Dissertação (Mestrado em Tecnologia e Inspeção de Produtos de Origem Animal) - Escola de Veterinária da Universidade Federal de Minas Gerais, Belo Horizonte, 2016.
SUÁREZ, J. E. Microbiota autóctona, probióticos y prebióticos. Nutrición Hospitalaria, v. 31, n. supl. 1, p. 3-9, 2015. DOI: $10.3305 /$ nh.2015.31.sup 1.8701

SUZUKI, M.; RAPPÉ, M. S.; GIOVANNONI, S. J. Kinetic bias in estimates of coastal picoplankton community structure obtained by measurements of small-subunit rRNA gene PCR amplicon length heterogeneity. Applied and Environmental Microbiology, v. 64, n. 11, p. 4522-4529, 1998.

VENTURA, M.; TURRONI, F.; VAN SINDEREN, D. Probiogenomics as a tool to obtain genetic insights into adaptation of probiotic bacteria to the human gut. Bioengineered Bugs, v. 3, n. 2, p. 73-79, 2012. DOI: $10.4161 /$ bbug. 18540

WENDLING, L. K.; WESCHENFELDER, S. Probióticos e alimentos lácteos fermentados - uma revisão. Revista do Instituto de Laticínios Cândido Tostes, v. 68, n. 395 , p. 49-57, 2013. DOI: $10.5935 / 2238$ 6416.20130048 